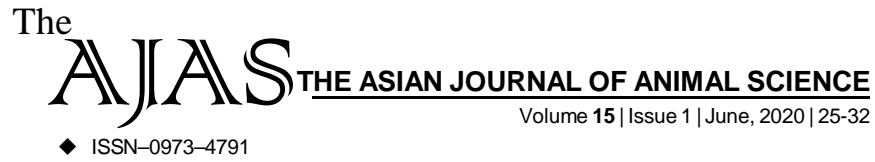

DOI : 10.15740/HAS/TAJAS/15.1/25-32 Visit us | www.researchjournal.co.in

A REVIEW

\title{
Challenges of emerging and re-emerging salmonellosis
}

Chandra Shekhar

Author for Corresponding -

\section{Chandra Shekhar}

Department of Veterinary Public

Health and Epidemiology,

College of Veterinary Science and

Animal Husbandry, Acharya

Narendra Deva University of

Agriculture and Technology,

Kumarganj, Ayodhya (U.P.)

India

Email: cshekharvph@gmail.com
ABSTRACT...... Salmonellosis is an infectious disease of animals and humans caused by various Salmonella serovars. It is one of the most common and economically important foodborne zoonotic diseases in humans. Millions of human cases of salmonellosis are reported worldwide every year resulting into thousands of deaths. Infection in food animals may lead to contamination of milk, meat and eggs, and their products. The population of highly susceptible persons is expanding worldwide. There are various risk factors like occupation, age, health status, immune status, medication and infection with MDR Salmonella strains that may increase the incidence of salmonellosis and its severity in animals and humans. There are various factors like season, housing, hygienic conditions, population density, deprivation of food, stress, intensive husbandry system and contaminated pastures that influence the occurrence of salmonellosis. Factors like environmental changes, changes in human demographics and behaviour, changes in consumer lifestyle, microbial adaptation and change, technological changes and industrialization, economic development and land use, breakdown of host's defenses, breakdown of public health measures and international travel and trade contribute to emergence and re-emergence of salmonellosis worldwide. Salmonella infections in animals and humans can be prevented and controlled by adopting strict hygienic measures, proper treatment and disposal of sewage, regular disinfection of water, health education of public, avoiding handling and preparation of foods by infected individuals and carriers in any food production and processing establishments, adequate heat treatment of foods, avoiding contacts with animals and human reservoirs and carriers, vaccination (against typhoid and paratyphoid fever), treatment of infected individuals, continuous epidemiological surveillance of Salmonella in both animals and humans and international reporting of Salmonella outbreaks.

KEY WORDS...... Salmonella, Salmonellosis, Prevalence, Emerging, Re-emerging

HOW TO CITE THIS ARTICLE - Shekhar, Chandra (2020). Challenges of emerging and re-emerging salmonellosis. Asian J. Animal Sci., 15(1): 25-32.DOI:10.15740/HAS/TAJAS/15.1/25-32. Copyright@ 2020:HindAgri-Horticultural Society.

ARTICLE CHRONICLE - Received : 06.02.2020; Accepted : 23.05.2020 